Open Access

\title{
The advance care planning PREPARE study among older Veterans with serious and chronic illness: study protocol for a randomized controlled trial
}

Rebecca Sudore ${ }^{1,2^{*}}$, Gem M. Le ${ }^{1,3}$, Ryan McMahan ${ }^{2}$, Mariko Feuz ${ }^{2}$, Mary Katen ${ }^{2}$ and Deborah E. Barnes ${ }^{1,4,5}$

\begin{abstract}
Background: Advance care planning (ACP) is a process whereby patients prepare for medical decision-making. The traditional objective of ACP has focused on the completion of advance directives. We have developed a new paradigm of ACP focused on preparing patients and their loved ones for communication and informed medical decision-making. To operationalize this new paradigm of ACP, we created an interactive, patient-centered website called PREPARE (www.prepareforyourcare.org) designed for diverse older adults.

Methods/Design: This randomized controlled trial with blinded outcome assessment is designed to determine the efficacy of PREPARE to engage older Veterans in the ACP process. Veterans who are $\geq 60$ years of age, have $\geq$ two medical conditions, and have seen a primary care physician $\geq$ two times in the last year are being randomized to one of two study arms. The PREPARE study arm reviews the PREPARE website and an easy-to-read advance directive. The control arm only reviews the advance directive. The primary outcome is documentation of an advance directive and ACP discussions. Other clinically important outcomes using validated surveys include ACP behavior change process measures (knowledge, contemplation, self-efficacy, and readiness) and a full range of ACP action measures (identifying a surrogate, identifying values and goals, choosing leeway or flexibility for the surrogate, communicating with clinicians and surrogates, and documenting one's wishes). We will also assess satisfaction with decision-making and Veteran activation within primary care visits by direct audio recording. To examine the outcomes at 1 week, 3 months, and 6 months between the two study arms, we will use mixed effects linear, Poisson, or negative binomial regression and mixed effects logistic regression.
\end{abstract}

Discussion: This study will determine whether PREPARE increases advance directive completion rates and engagement with the ACP process. If PREPARE is efficacious, it could prove to be an easy and effective intervention to help older adults engage in the ACP process within or outside of the medical environment. PREPARE may also help older adults communicate their medical wishes and goals to their loved ones and clinicians, improve medical decision-making, and ensure their wishes are honored over the life course.

Trial registration: ClinicalTrials.gov NCT01550731. Registered on 8 December 2011.

Keywords: advance care planning, aging, medical decision-making, randomized trial, chronic disease management, geriatrics, veterans, health behavior, advance directive, vulnerable populations

\footnotetext{
* Correspondence: rebecca.sudore@ucsf.edu

'Division of Geriatrics, Department of Medicine, University of California, San

Francisco, 3333 California St. Suite 380, San Francisco, CA 94143, USA

${ }^{2}$ San Francisco Veterans Administration Medical Center, 4150 Clement Street,

\#151R, San Francisco, CA 94121, USA

Full list of author information is available at the end of the article
}

C Biomed Central (c) 2016 Sudore et al. Open Access This article is distributed under the terms of the Creative Commons Attribution 4.0 International License (http://creativecommons.org/licenses/by/4.0/), which permits unrestricted use, distribution, and reproduction in any medium, provided you give appropriate credit to the original author(s) and the source, provide a link to the Creative Commons license, and indicate if changes were made. The Creative Commons Public Domain Dedication waiver (http://creativecommons.org/publicdomain/zero/1.0/) applies to the data made available in this article, unless otherwise stated. 


\section{Background}

More than 10 million Veterans who are over age 65 will face complex decisions over the course of chronic illness [1], yet most are unprepared to do so [2, 3]. Inadequate preparation leads to uninformed choices, lack of empowerment in clinical encounters, and added stress for Veterans, their families and surrogate decision makers [4-8]. Interventions to prepare Veterans for complex decisions and to communicate their wishes and goals for medical care to surrogates and clinicians are lacking.

Advance care planning is a process whereby people identify and communicate their goals for future medical care. In the old, narrow paradigm of advance care planning (ACP), the objective was focused on having patients make decisions about life-prolonging procedures, such as cardiac resuscitation, and to document these choices in an advance directive. However, Veterans are making many decisions over the course of their lives, and many Veterans and their loved ones are unprepared to make these decisions or to understand and complete legal advance directive forms, which are often used for advance care planning. More preparation is needed to achieve comprehensive ACP, and ACP guides must meet the literacy needs of older adults and Veterans $\left(5^{\text {th }}\right.$-grade level), as well as address patients' diverse cultural needs [9-12].

Our prior work addressed some of these barriers to meaningful ACP for older adults. We designed and tested an advance directive written at a $5^{\text {th }}$-grade reading level among 205 chronically ill, diverse, older adults at a county hospital in San Francisco. The easy-to-read directive was preferred over a standard directive, especially among those with limited health literacy. It also resulted in significantly greater 6-month advance directive completion rates, doubling the rates from baseline [12]. This easy-to-read advance directive is currently being disseminated in several languages in California [13].

Although the easy-to-read advance directive was shown to be an improvement over standard forms, through additional formative work, we found that most patients go through a series of ACP behavioral steps that extend beyond simply filling out an advance directive. For example, 6 months after exposure to the easy-to-read advance directive, only $13 \%$ completed an advance directive whereas $61 \%$ of older adults contemplated ACP, $56 \%$ discussed ACP with family or friends and $22 \%$ discussed ACP with clinicians [14]. These data support the need to engage patients in a full range of ACP activities in addition to having them complete legal advance directive forms.

Based on our prior work [15] and the work of others $[16,17]$, we developed and published an updated paradigm of comprehensive ACP that shifts the focus from completion of advance directives to preparing patients to communicate their goals of care with surrogates and to actively participate with clinicians in making the best possible in-the-moment decisions [11]. To operationalize this new paradigm, we created an easy-toread, culturally-appropriate website called PREPARE (www.prepareforyourcare.org). PREPARE is targeted to a $5^{\text {th }}$ - grade reading level and was designed to be completed outside of a clinical setting without supervision or facilitation. PREPARE includes communication training on how to 1 ) choose and ask a surrogate; 2 ) clarify and communicate one's values; 3 ) discuss leeway in surrogate's decisions (allow surrogates to use their best judgment); 4) inform clinicians, family, and friends of one's decisions; and 5) ask clinicians appropriate questions to make informed medical choices [11]. Extensive videos are used to demonstrate, through modeling, how to make ACP decisions and to communicate with surrogates and clinicians $[15,18-20]$. Our pilot findings showed that, among diverse older adults, PREPARE significantly improved engagement and behavior change in ACP. Furthermore, it was rated a 9 out of 10 for ease of use, despite limited health literacy and lack of computer experience in this cohort of older adults [15].

The goal of this randomized controlled trial is to determine the efficacy of PREPARE to engage Veterans in the full comprehensive process of ACP. Consistent with prior studies in the field, our primary outcome is advance directive completion. In addition, important secondary outcomes include identifying goals for medical care, communicating with surrogates and clinicians, and making informed medical decisions.

\section{Methods/Design}

\section{Theoretical foundation}

The conceptual framework for the PREPARE intervention and this study has been previously published [15]. In brief, this work rests on the foundation of Social Cognitive Theory, the Interpersonal Communication Competence Model, and Behavior Change Theory [18, 19, 21]. ACP is a complex behavior that often involves people undergoing a series of behavior change steps, which are influenced by knowledge, self-efficacy and readiness. Behavior change is highly influenced by social norms and modeling of these behaviors by others. This framework demonstrates that PREPARE was designed to address important moderator variables such as culture, religion, and literacy. PREPARE incorporates important aspects from the aforementioned theories by including training in communication, goal setting exercises and videos that demonstrate and model ACP behaviors. PREPARE is designed to address modifiable mediators such as knowledge, self-efficacy, and readiness, which then allows individuals to progress through the behavior change stages from pre-contemplation to contemplation and then to readiness and action for the 
multiple behaviors that compose the process of ACP. Based on the conceptual framework, we developed and validated the ACP Engagement Survey to measure the full construct and process of ACP [22]. Behavioral process measures of behavior change include knowledge, contemplation, self-efficacy, and readiness, whereas ACP actions include identification of a surrogate, identification of values and goals, choosing the level of leeway or flexibility in decision-making for the surrogate, communicating this information with clinicians and surrogate decision makers, and documenting one's wishes.

\section{Aims and primary hypotheses}

The primary hypothesis of this study is that older Veterans randomized to the PREPARE arm (the PREPARE website plus the easy-to-read advance directive), compared to the control arm (the easy-to-read advance directive alone), will have increased rates of ACP documentation in their medical record (advance directives, clinicians notes, code status orders). Because this is the standard outcome measure for advance care planning, it is the outcome on which we calculated our sample size (see Sample Size Section). However, ACP consists of several behavioral processes (knowledge, contemplation, self-efficacy, and readiness) for several discrete ACP behaviors, including identifying surrogates, identifying values, and communicating this information with clinicians, surrogates, and other loved ones. Therefore, we feel our secondary outcomes and hypotheses are just as clinically meaningful. The secondary hypotheses of this study are that older Veterans randomized to the PREPARE arm, compared to the control arm, will have greater engagement in ACP including behavior change process measures and additional ACP actions beyond advance directive documentation as measured by a validated survey [22]. Secondary hypotheses also include greater Veteran activation and clinician responsiveness within the clinical encounter as measured by audio-recording a subset of clinical visits, Veteran satisfaction with clinician communication, Veteran engagement and satisfaction with decision-making, surrogate-reports of Veteran engagement in ACP behaviors, and fewer reported barriers to ACP for the PREPARE versus control arm. Other outcomes include comparisons of acceptability and usability of the PREPARE website plus an easy-to-read advance directive versus an advance directive alone (Table 2).

\section{Setting}

The study is a randomized controlled trial with blinded outcome ascertainment conducted at the San Francisco Veterans Administration Medical Center (SFVAMC).

\section{Overview of study procedures}

Veteran recruitment occurs in waves to target upcoming primary care clinic appointments and to allow time for recruitment and scheduling of a baseline interview (Fig. 1, Study Flowchart). Veterans are then randomized to the PREPARE arm (PREPARE website [15], action plan creation within the website, and provision of PREPARE logins and PREPARE materials in pamphlet, booklet and DVD formats to take home) plus an easy-to-read advance directive [12], or the control arm which only receives the easy-to-read advance directive. Outcomes pertaining to $\mathrm{ACP}$ engagement behavior are assessed at 1 week, 3 months, and 6 months between the two study arms (Table 2).

\section{Participants}

Table 1 includes a list of all inclusion and exclusion criteria. Briefly, Veterans are eligible for inclusion in this study if they are 60 years of age and older and have two or more chronic or severe medical conditions as determined by any of the ICD-9 codes listed in the Charlson or Elixhauser measures of comorbidity [23, 24]. The Charlson comorbidity index uses ICD-9 codes associated with 22 comorbid conditions such as heart disease and cancer, and the Elixhauser uses 30 acute and chronic conditions associated with in-patient mortality. We use the inclusion criteria of two or more chronic or severe medical conditions to identify a cohort of patients who have medical conditions that may require medical decision-making. Patients also have to have been seen by a primary care clinician at the SFVAMC two or more times in the past year (a marker for established primary care) and have two or more additional outpatient or inpatient visits in the past year (a marker of disease severity and frequent access to care). Patients are excluded if they have dementia; are blind, deaf, or psychotic as determined by their clinician, chart review or study staff; do not have a phone for study contact and follow-up interviews; or do not live within 30 miles of the SFVAMC, which would make an in-person baseline interview difficult (Table 1). We chose to focus our study population on older adults with chronic illness, as our preliminary work suggests that patients may be less likely to engage in ACP if they perceive themselves as "too healthy" [25]. In addition, we chose not to exclude patients with terminal or serious illness because our goal is to move ACP upstream in patients' disease trajectories and to assess the efficacy of PREPARE across a range of health statuses.

The SFVAMC Veteran population consists of approximately $4 \%$ women [1]. Therefore, we increased recruitment of women by working closely with the SFVAMC Women's Clinic and oversampling women through our patient recruitment call lists. To ensure a diverse sample, we also oversampled minorities in an attempt to obtain a cohort of $50 \%$ white and $50 \%$ non-white Veterans. Oversampling is feasible as the racial/ethnic variation of SFVAMC outpatients is approximately $55 \%$ white, $29 \%$ 


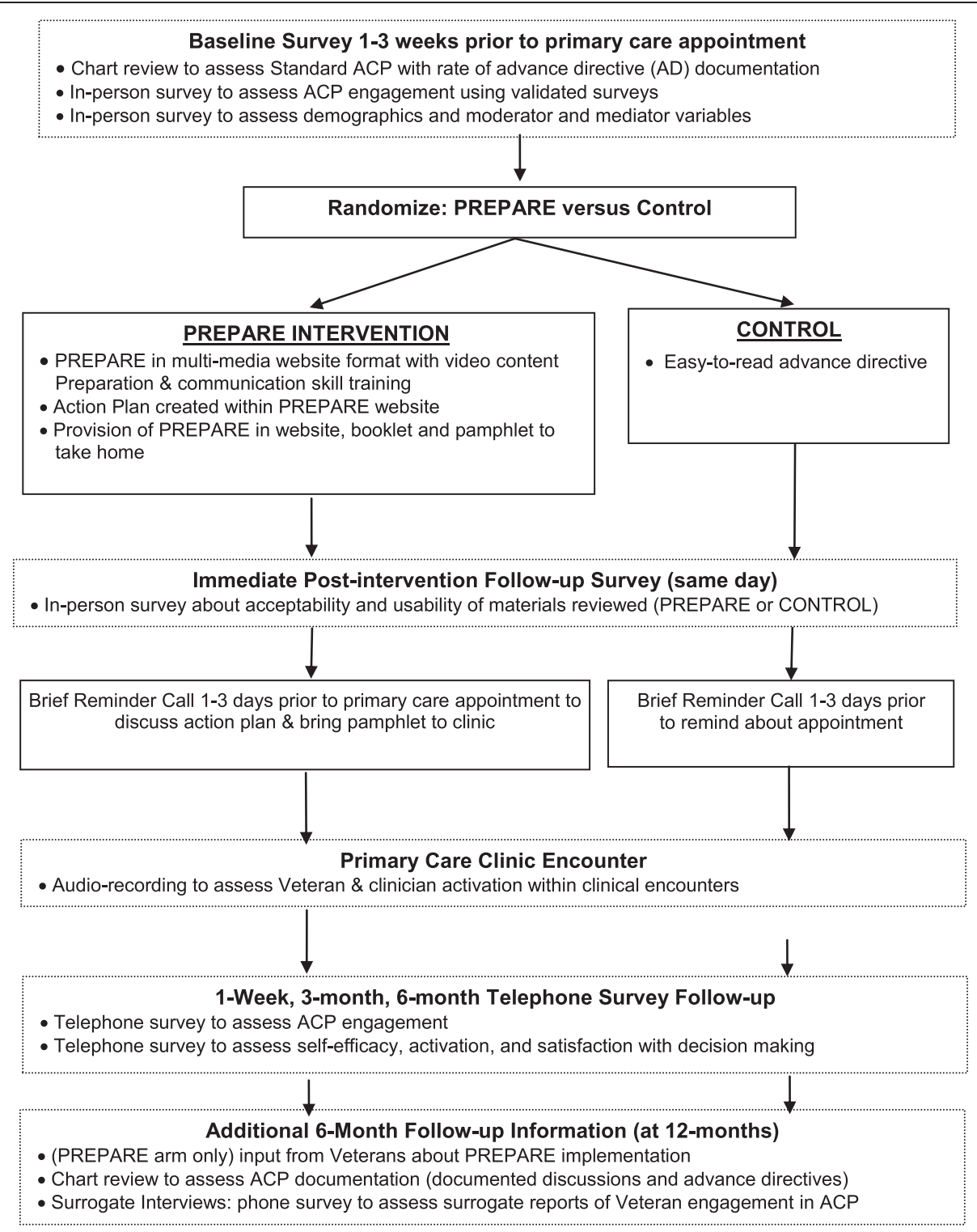

Fig. 1 Flowchart of the PREPARE Trial

black, $8 \%$ Latino, $6 \%$ Asian/Pacific Islander, and $2 \%$ other [26].

For a subset of enrolled participants, we also include Veteran's self-identified surrogate decision-makers. Surrogates are included if the Veteran identifies her or him and gives the study team permission to contact them. Surrogates are excluded if they had dementia or are blind, deaf, or psychotic as determined by the study staff (Table 1 ).

\section{Recruitment}

\section{Health Insurance Portability and Accountability Act} (HIPAA) waiver

To facilitate recruitment, we obtained a HIPAA waiver to access data from VA administrative records on patients' names, age, race/ethnicity, gender, phone numbers, addresses, medical record numbers, ICD-9 codes, dates of outpatient primary care clinic appointments in the past year and up to 3 months in the future, hospitalizations and emergency room visits in the past year, and the name of their outpatient primary care provider. All data is stored on secure, password-protected servers or in locked research offices. Access is restricted to the study team for recruitment purposes only.

\section{Data extraction}

After obtaining a HIPAA waiver, we obtained a list of potential Veteran participants who met initial eligibility criteria described in Table 1 and a list of their primary care physicians. 
Table 1 Inclusion and exclusion criteria by type of study participant

\begin{tabular}{|c|c|}
\hline \multicolumn{2}{|l|}{ Veteran patient } \\
\hline \multirow[t]{3}{*}{ Inclusion criteria } & 60 years of age or older \\
\hline & $\begin{array}{l}\text { Obtains care in the primary care clinics (General } \\
\text { Medicine, Geriatrics, and Women's Clinic) at the } \\
\text { San Francisco VA Medical Center }\end{array}$ \\
\hline & $\begin{array}{l}\text { Has been seen at least twice in the last year by a } \\
\text { primary care provider (a measure of established } \\
\text { primary care) and had at least two additional visits } \\
\text { to the VA in the past year (a measure of frequent the } \\
\text { medical center) }\end{array}$ \\
\hline \multirow[t]{10}{*}{ Exclusion criteria } & $\begin{array}{l}\text { Dementia by ICD-9 codes, clinician assessment, chart } \\
\text { review or self-report }\end{array}$ \\
\hline & $\begin{array}{l}\text { Blindness or poor vision by ICD-9 codes, clinician } \\
\text { assessment, chart review, self-report of blindness or } \\
\text { the inability to read print on a newspaper, or research } \\
\text { staff assessment of less than } 20 / 200 \text { vision on the } \\
\text { Snellen eye chart with corrective lenses [42]. }\end{array}$ \\
\hline & $\begin{array}{l}\text { Deafness by ICD-9 codes, clinician assessment, } \\
\text { self-report, chart review or research staff assessment }\end{array}$ \\
\hline & $\begin{array}{l}\text { Cognitive impairment as assessed by research staff of } \\
\text { any deficits on the validated cognitive assessments } \\
\text { Short Portable Mental Status Questionnaire (SPMSQ) } \\
\text { [43] and the mini-Cog [44] }\end{array}$ \\
\hline & $\begin{array}{l}\text { Delirium or psychosis as assessed by a clinician or } \\
\text { research staff }\end{array}$ \\
\hline & Does not report fluency in English \\
\hline & $\begin{array}{l}\text { No phone for additional study contacts and follow-up } \\
\text { interviews }\end{array}$ \\
\hline & $\begin{array}{l}\text { Active drug or alcohol abuse within the past } \\
3 \text { months determined by clinician assessment, } \\
\text { self-report, chart review or research staff assessment }\end{array}$ \\
\hline & $\begin{array}{l}\text { Patients who report they will be out of town during } \\
\text { their scheduled follow-up interview dates outside of a } \\
\text { window of } 2 \text { months }\end{array}$ \\
\hline & $\begin{array}{l}\text { Patients who cannot answer consent teach-back } \\
\text { questions after three attempts }\end{array}$ \\
\hline \multicolumn{2}{|c|}{ Surrogate participant } \\
\hline \multirow[t]{3}{*}{ Inclusion criteria } & 18 years of age or older \\
\hline & $\begin{array}{l}\text { An enrolled patient must identify the surrogate as } \\
\text { someone who could make medical decisions for him } \\
\text { or her if needed }\end{array}$ \\
\hline & $\begin{array}{l}\text { An enrolled patient must give the surrogate's contact } \\
\text { information and give permission to contact their } \\
\text { potential surrogate }\end{array}$ \\
\hline Exclusion criteria & Self-reported dementia, blindness, or deafness \\
\hline
\end{tabular}

Cognitive impairment as assessed by research staff of any deficits on the validated cognitive assessments Short Portable Mental Status Questionnaire (SPMSQ) [43] and the mini-Cog [44]

Delirium or psychosis as assessed by research staff

Does not report fluency in English

No phone for follow-up interviews

Surrogates who report they will be out of town during their scheduled follow-up interview dates outside of a window of 2 months
Table 1 Inclusion and exclusion criteria by type of study participant (Continued)

\author{
Surrogate for whom we cannot schedule an interview \\ greater than 6 months from the Veteran's final \\ 6-month follow-up interview date \\ Surrogates for whom we have attempted to contact \\ 5 times or more without a response \\ Surrogates who cannot answer consent teach-back \\ questions after three attempts
}

\section{Clinician involvement}

Upon completion of the administrative data pulls and identification of potentially eligible Veterans, primary care providers are then sent an e-mail letter informing them about the research study. The email also asks providers to give their permission for our study staff to contact their patients and tell them more about the study. A list of the clinician's patients is provided, and clinicians are given the option to opt out for all patients, approve for all of their patients, or review the patient list to identify individual patients whom they feel are either appropriate or inappropriate for our study. We also ask permission of clinicians to allow us to send their potentially eligible patients a recruitment letter stating that the clinician gave permission to tell them more about a research study. Clinicians can opt out of having their name used in the patient recruitment letter. Clinicians are informed that if they did not respond to our emails or phone calls within three attempts, we will assume assent for the study. If clinicians do not respond after three attempts over 3 weeks to our requests to grant permission to contact their patients, we send a generic, nonpersonalized recruitment letter describing the study to potential participants on behalf of the study team. If a clinician gives us explicit permission to contact their patients, we inform patients that their individual doctor gave us permission to contact them and tell them about the study. Otherwise, we describe the study without mentioning their clinician.

\section{Targeted patient recruitment by letter}

The recruitment letter to patients describes the research study and gives patients a toll-free telephone number to call to opt-out or to hear more about the study. Potential participants who do not call study staff to decline participation within 1 week of the mailings are deemed eligible to be contacted by phone to further describe the study and assess willingness to participate and study eligibility. Additional waves of patient recruitment letters will be sent out two to three times per year to enhance our recruitment efforts. 


\section{Targeted patient recruitment by phone}

We attempt to schedule Veterans for the baseline interview and exposure to the intervention 1 to 3 weeks prior to their next upcoming primary care appointment. This is done to standardize the timing between intervention exposure and primary care follow-up. Therefore, for Veterans who do not send back an opt-out letter or call to refuse participation, we attempt recruitment by phone. Targeted data pulls are created to determine which Veterans have upcoming primary care appointments at least 2 weeks in the future. This time frame was selected to allow time to screen and schedule consent and baseline interviews 1 to 3 weeks prior to the primary care visit. The order of Veterans' names on the recruitment call lists is randomly "scrambled" to prevent biased sampling. In addition, women and minority Veterans are prioritized on the call list in an attempt to oversample during phone recruitment.

\section{Recruitment fliers}

Study-related fliers written at a $5^{\text {th }}$-grade reading level are posted in approved areas in the primary care clinics at the SFVAMC. Potential participants who read a study flier can opt-in to the study by contacting study staff via our toll-free number.

\section{Surrogate recruitment}

Once Veterans are enrolled in the study, we obtain a consecutive sample of English-speaking surrogates through Veteran referral. For Veterans who grant us permission to contact their potential surrogate, we obtain contact information for the surrogate from the enrolled Veteran. We also ask the Veteran participant to give the potential surrogate participant our study flier and/or let them know we would be contacting them. Depending upon the type of contact information we are given by the Veteran, we may contact the potential surrogate participant in the clinic, if they accompanied a Veteran participant, or by phone, email, or mail.

\section{Screening for eligibility of Veterans and surrogates}

Interested Veteran participants and surrogates are screened for eligibility based on the exclusion criteria in Table 1. Specifically, research staff exclude individuals who report not having a phone, Veterans who are less than 60 years of age, and Veterans or surrogates who test positive for moderate-to-severe cognitive impairment on the Short Portable Mental Status Questionnaire (SPMSQ) as indicated by more than three errors and who then also fail to recall at least two out of three items on the three-item recall of Mini-Cog [27, 28]. Participants are also excluded if they self-reported having dementia, poor vision (unable to see the words on a newspaper), or being unable to speak English well or very well.

\section{Consent procedures}

\section{Written consent for patients}

Informed consent will be or has been obtained from all study participants. We use a modified consent process we designed to help vulnerable populations make informed decisions about study participation [29]. This process involves using a consent form written at a $5^{\text {th }}$ grade reading level, reading and paraphrasing the consent form to potential subjects, allowing time for questions and discussion, and then assessing comprehension about the study via the teach-back method. Patients are also able to read the form independently if they wished. If comprehension questions during teach-back are not answered correctly, repeated education and reassessment of comprehension are continued until complete comprehension is achieved. If subjects cannot pass the teach-back process and comprehension assessment after three attempts, the patient is deemed ineligible for the study.

\section{Electronic or written consent for clinicians to be audio-recorded}

We obtain either an e-consent or written consent for clinicians to be audio-recorded during primary care visits, to answer one demographic question about their race/ethnicity, and to allow us to contact them in the future if we have further questions about their enrolled patients. The e-consent is emailed to clinicians on secure email servers. If clinicians cannot be reached by email, we obtain written consent in-person.

\section{Verbal and written consent for surrogates}

Some patients' surrogate decision-makers may live outside of the area (in a different state), or cannot come to the VA for in-person informed consent. Initially, a waiver of signed consent for surrogates was not approved. At this time, a signed written consent form is required prior to any surrogate interviews. To accomplish this, we mail a consent form to the surrogate, review the consent form and conduct consent verification over the phone. The surrogate is then given a stamped and addressed envelope to return the signed consent form. After consent is obtained, we can then call and schedule a phone or in-person interview. This is time consuming and can result in several (up to 10) attempts to contact the surrogate. Therefore, we now obtain a written consent waiver for surrogates. After calling a potential surrogate participant, if they answer all questions on the consent verification accurately within three tries, the surrogate can provide verbal consent over the phone, and we can continue with the study interview. If the surrogate is available in person, then a written informed consent form is reviewed and signed. All surrogates are still required to complete and return a signed 
HIPAA authorization by mail for their interview information to be used in the study.

\section{Intervention and control conditions}

After the baseline interview, participants in the PREPARE arm review the PREPARE website (www.prepareforyourcare.org) in the research offices. Research staff are available to answer questions, but participants are asked to go through the PREPARE website (Steps 1 through 5) on their own and in its entirety. As participants progress through the website, PREPARE asks questions about overall life values and goals for medical care. At the end of the program, the participant is asked to make an action plan to do one ACP task in the next weeks to months. At the end of the interview, research staff print out the action plan and a summary of the Veteran's medical wishes and compile this into a folder that also contains the PREPARE pamphlet, booklet, DVD, and the log-in code to the website. The PREPARE DVD contains the same information found on the website, but without interactive or tailored functionality. PREPARE arm participants are also given an easy-to-read advance directive to review and take home (http://www.iha4health.org/ourservices/advance-directive/) [13]. Participants in the control arm are only given the advance directive, are asked to review it for at least 10 minutes and to take it home. The control arm is not given any information about the PREPARE materials. One to 3 days before the Veteran's next scheduled primary care appointment, research staff call the PREPARE arm participants to remind them to bring in their action plan, summary of wishes and advance directive to their doctor's appointment. For the control arm, research staff members only remind Veterans about their upcoming primary care appointment.

\section{Randomization procedures}

We block randomize Veterans based on limited health literacy, as determined by a validated question concerning confidence with medical forms [30], and non-white race/ ethnicity to ensure these variables are equally distributed between randomization groups. A statistician not involved in recruitment or data collection used a computer-based random number generator to create a randomization scheme within four groups (high health literacy and white race/ethnicity, high health literacy and non-white race/ ethnicity, low health literacy and white race/ethnicity, and low health literacy and non-white race/ethnicity) in random block sizes of 4,6 , and 8 . This randomization scheme was imported into the Research Electronic Data Capture (REDCap) software by the statistician. Only the research personnel who conducted the baseline interview use this software prior to the baseline interview to determine which study arm the Veteran is assigned to and which ACP interventions (PREPARE versus control) to give the enrolled participant. Randomization information is kept separate from other research or identifying Veteran data and is only associated with a unique Veteran identification number.

\section{Blinding}

Participants are blinded to group assignment. They are told that the purpose of the study is to help patients make difficult medical decisions, and that each participant would review one of two guides. This blinding is enhanced by each group obtaining some form of ACP materials, such as the easy-to-read advance directive. To ensure blinding of research staff for all follow-up outcome assessments, staff who had completed the baseline interview and randomization for a given participant will not conduct any follow-up interviews with that participant.

\section{Intervention fidelity}

A study protocol manual was created for research staff, and several training sessions have been and will continue to be conducted until the end of the study. In addition, we have created standardized study scripts for recruitment and interviewing and have created training videos to standardize the study procedures. Checklists for all follow-up assessments have also been created. All staff being trained need to learn each item on the checklist, shadow other study staff, and be evaluated by their supervisors for each checklist item. Study staff cannot conduct PREPARE study tasks independently until they can demonstrate mastery of each checklist item. After study staff members are considered independent to conduct study tasks and interviews, a $10 \%$ random sample of interviews will be observed to ensure fidelity to study procedures. Data collection initially began with paper surveys that were entered into a REDCap survey capture database. At least $50 \%$ of the data entry was reviewed by an independent staff member to ensure data were entered correctly. Part way through our study, we switched to live data capture through REDCap. This allows us to streamline our data entry procedures and reduce the use of printed paper surveys. To reduce missing data, automatic prompts have been created within the REDCap program that will not allow study staff to progress if a question is left blank. Concerns about question wording or response option interpretation are reviewed at regular team meetings.

\section{Ethics}

This study has been approved by the University of California, San Francisco (UCSF) and the San Francisco VA Medical Center institutional review boards (UCSF IRB reference \# 10-00098) and is registered at ClinicalTrials.gov (NCT01550731). This study is funded by the United 
States Veterans Administration, Health Services Research and Development.

\section{Measures and data collection}

A range of measures are collected to capture the full process of ACP and whether the PREPARE intervention has any effect on ACP, medical decision-making, patient activation, clinician responsiveness, and doctor-patient communication. Table 2 lists all study measures assessed at multiple time points. Details of the main outcome measures are described below.

\section{Measures related to advance directive and $A C P$ documentation}

Standard ACP is measured by the completion of advance directives in the VA electronic medical record. We will assess baseline advance directive completion rates and the date the advance directive was signed as well as ACP discussions. At 6 months (date of the last follow-up interview), we reassess the advance directive completion rate and the date it was signed to determine length of time from study enrollment to documentation. An advance directive for the purposes of this study includes the VA or easy-to-read advance directive, a living will, a durable power of attorney for health care document (DPOAHC), a Physicians Orders of Life Sustaining Treatment form, or other documentation of the patient's wishes for medical care (code status, such as full code or do not resuscitate or do not intubate orders by a physician).

\section{Measures related to $A C P$ engagement including behavior change process measures and ACP actions}

Full ACP engagement is measured by Veteran self-report at baseline, 1 week, 3 months, and 6 months. Based on Social Cognitive Theory and Behavioral Change Theory $[18,19]$, we included measures to capture theoretical constructs related to contemplation of behavior, planning or intention to act on the behavior, and the behavior itself. If only the action behavior is measured, such as completion of an advance directive, clinically significant movement along the behavior change pathway will be missed. Thus, it is important to ascertain ACP process measures of behavior change (knowledge, contemplation, self-efficacy, and readiness) for several ACP actions in addition to whether they have completed an ACP behavior (Action Measures). These actions include 1) identifying of a surrogate, 2) identifying values and goals, 3) choosing the level of leeway or flexibility in decision-making for the surrogate, 4) and communicating this information with clinicians and surrogate decision makers, and 5) documenting one's wishes [22]. As Veterans may have had varying degrees of experience with $\mathrm{ACP}$, we assess baseline engagement in ACP within the past 5 years (standardized based on pilot data). We also ask about engagement in
ACP since the randomization date, for example, "Within the past one week, 3 or 6 months", depending upon the follow-up interval.

\section{Validity and reliability of the ACP Engagement Survey}

In a prior study, we established the validity and reliability of the ACP engagement survey in 50 older adults, aged 60 years or older with two or more chronic or serious illnesses $(32 \%$ female, $42 \%$ non-white). Internal consistency of the survey was high with a Cronbach's alpha of 0.94 for Process Measures. Seven-day test-retest reliability was also high with interclass correlations of 0.70 for Process Measures and 0.87 for Action Measures. We also tested discriminant validity by comparing process and action scores for older adults to healthy young adults and found statistically significant differences [22]. Furthermore, this survey has been used in pilot testing and has been shown to be able to detect ACP behavior change in response to the PREPARE website [15].

\section{Measures related to engagement and satisfaction in decision-making}

Engagement in decision-making is measured with two items (Table 2, desired role in decision-making). Satisfaction with decision-making is assessed with the Decisional Conflict scale for those who report a decision was made [31]. The Decisional Conflict scale consists of three subscales assessing decisional uncertainty, factors contributing to uncertainty, and decisional effectiveness.

\section{Measures related to surrogate decision maker reports of Veteran engagement}

Because the preparation guide is highly focused on communication with one's surrogate, it is important to measure whether Veterans engage in preparation behaviors with his/her potential surrogate for important corroborating information. We ask yes/no questions for all 5 preparation domains (Table 2, surrogate reports of patient engagement in ACP and other surrogate items). Surrogates are also asked about their knowledge of the Veteran's wishes and confidence in making decisions on the Veteran's behalf on a 5-point Likert scale with response options from "not at all" to "extremely".

\section{Measures related to acceptability and usability of PREPARE versus control}

Acceptability and usability of PREPARE compared to an advance directive alone are measured with validated scales from our prior work according to the following: (a) ease of use and understanding (8-item scale), (b) personal usefulness in treatment decisions and discussions (6-item scale), and (c) attitudes about norms or expectations (6-item scale) [12]. We also assess how comfortable the Veterans are in completing the forms and the website, how helpful they find the materials, and how likely they are to recommend the 
Table 2 Constructs and measures for evaluating the efficacy of the PREPARE Study

\begin{tabular}{|c|c|c|c|c|c|c|c|c|}
\hline Construct & Measure & \# items & Reliability/validity & Screener & Baseline & 1 week & 3 month & 6 month \\
\hline & Eligibility screening variables & & & & & & & \\
\hline \multirow[t]{4}{*}{ Cognitive impairment } & $\begin{array}{l}\text { Short Portable Mental Status } \\
\text { Questionnaire (SPMSQ) }\end{array}$ & 7 & $\begin{array}{l}\text { Sensitivity } 86.2 \%, \\
\text { specificity } 99.0 \%[43]\end{array}$ & $x$ & & & & \\
\hline & 0 to 2 = eligible & & & & & & & \\
\hline & $\begin{array}{l}3 \text { to } 7 \text { moderate impairment (go on } \\
\text { to the Mini Cog three-item recall) }\end{array}$ & & & & & & & \\
\hline & $\geq 8$ severe impairment $=$ ineligible & & & & & & & \\
\hline \multirow{2}{*}{$\begin{array}{l}\text { Cognitive impairment } \\
\text { (participants scoring } \\
3 \text { to } 7 \text { errors on the } \\
\text { SPMSQ) }\end{array}$} & $\begin{array}{l}\text { Mini Cog (three-item recall as } \\
\text { needed, if SPMSQ screen + for } \\
\text { cognitive impairment) }\end{array}$ & 3 & $\begin{array}{l}\text { Sensitivity } 76 \% \\
\text { specificity } 89 \%[44]\end{array}$ & $x$ & & & & \\
\hline & If recall $\geq$ two words $=$ eligible & & & & & & & \\
\hline \multirow[t]{2}{*}{ Vision } & $\begin{array}{l}\text { Ability to see words on a } \\
\text { newspaper [42] }\end{array}$ & 1 & & & & & & \\
\hline & Moderator variables & & & & & & & \\
\hline Demographic information & $\begin{array}{l}\text { Age, gender, race/ethnicity [45], } \\
\text { income, marital status, and education }\end{array}$ & & & $x$ & $x$ & & & \\
\hline \multirow[t]{2}{*}{ Health literacy screen } & $\begin{array}{l}\text { "How comfortable are you filling } \\
\text { out medical forms by yourself?" }\end{array}$ & 1 & \multirow{2}{*}{$\begin{array}{l}\text { AUROC } 0.80 \\
(95 \% \mathrm{Cl}=0.67 .0 .93) \\
\text { for inadequate } \\
\text { health literacy [46] }\end{array}$} & $x$ & & & & \\
\hline & $\begin{array}{l}\text { "Qué tan seguro (a) se siente al llenar } \\
\text { formas usted solo (a)" }\end{array}$ & & & & & & & \\
\hline \multirow[t]{2}{*}{ Health literacy assessment } & \multirow{2}{*}{$\begin{array}{l}\text { Short form Test of Functional Health } \\
\text { Literacy in Adults s-TOFHLA, scores } \\
0 \text { to } 36 \text { ) [47] Continuous \& } \\
\text { dichotomized to limited = } 0 \text { to } 22 \\
\text { and adequate }=23 \text { to } 36\end{array}$} & 36 & Cronbach's $a=.97$ & & $x$ & & & \\
\hline & & & $\begin{array}{l}\text { Correlation } \\
\text { coefficient w/ other } \\
\text { literacy tests }>0.80[47]\end{array}$ & & & & & \\
\hline \multirow[t]{2}{*}{ United States acculturation } & \multirow{2}{*}{$\begin{array}{l}\text { Based on Acculturation scale (USAS) } \\
\text { "How many years have you lived in } \\
\text { the U.S.?" }\end{array}$} & 1 & Cronbach's $a=.98$ & & $x$ & & & \\
\hline & & & $\begin{array}{l}\text { Associated } w / \text { desire to } \\
\text { know prognosis [48] }\end{array}$ & & & & & \\
\hline Finances & $\begin{array}{l}\text { "In general, how do your finances } \\
\text { usually work out at the end of } \\
\text { the month?" }\end{array}$ & 1 & $\begin{array}{l}\text { Associated with } \\
\text { functional impairment } \\
\text { and comorbidity [49] }\end{array}$ & & $x$ & & & \\
\hline Socioeconomic status and social standing & $\begin{array}{l}\text { Social standing ladder (that is, place } \\
\text { an " } x \text { " where you think you stand } \\
\text { relative to other people in society) }\end{array}$ & 1 & $\begin{array}{l}\text { Associated with } \\
\text { functional decline [50] }\end{array}$ & & $x$ & & & \\
\hline Functional status & $\begin{array}{l}\text { Activities of Daily Living (ADL) and } \\
\text { Instrumental Activities of Daily } \\
\text { Living (IADL) }\end{array}$ & 15 & $\begin{array}{l}\text { Morbidity/mortality } \\
\text { correlation }[51,52]\end{array}$ & & $x$ & & & \\
\hline Self-rated health status & $\begin{array}{l}\text { In general how would you rate } \\
\text { your health? (5-pt Likert) }\end{array}$ & 1 & $\begin{array}{l}\text { Correlation with global } \\
\text { health, spearman's } \\
\text { rho }=-63 \text {, and } \\
\text { mortality [53] }\end{array}$ & $x$ & & & & \\
\hline Self-rated quality of life & $\begin{array}{l}\text { In general, how would you rate your } \\
\text { overall quality of life in the past } \\
\text { week (5-pt Likert) }\end{array}$ & 1 & $\begin{array}{l}\text { Test-retest } \\
\text { coefficient }=0.81[54]\end{array}$ & $x$ & & & & \\
\hline \multirow[t]{3}{*}{ Comorbid illness } & Determined by ICD-9 codes (chart) & 0 & Mortality c-stat: [23] & & $x$ & & & \\
\hline & Charlson comorbidity score [24] & & Charlson $=0.704$ & & & & & \\
\hline & Elixhauser comorbidity score [55] & & Elixhauser $=0.793$ & & & & & \\
\hline Social support & $\begin{array}{l}\text { Modified Medical Outcomes Study } \\
\text { Social Support (mMOS-SS) }\end{array}$ & 11 & $\begin{array}{l}\text { Cronbach's } \\
a=0.88-93[56]\end{array}$ & & $x$ & & & \\
\hline Religion/spirituality & $\begin{array}{l}\text { Self-reported extent of how } \\
\text { spiritual/religious (5-pt Likert) } \\
\text { and role play in decision-making. }\end{array}$ & 4 & $\begin{array}{l}\text { Spirituality associated } \\
\text { with quality of life. } \\
\text { Religiosity associated } \\
\text { with wanting all } \\
\text { measures to extend } \\
\text { life [57] }\end{array}$ & & $x$ & & & \\
\hline Prior ACP experience & $\begin{array}{l}\text { Prior ACP experiences (for example, } \\
\text { Ever had to make life threatening } \\
\text { medical decisions?") [12] }\end{array}$ & 5 & & & $x$ & & & \\
\hline
\end{tabular}


Table 2 Constructs and measures for evaluating the efficacy of the PREPARE Study (Continued)

\begin{tabular}{|c|c|c|c|c|c|c|c|c|}
\hline Construct & Measure & \# items & Reliability/validity & Screener & Baseline & 1 week & 3 month & 6 month \\
\hline \multirow[t]{2}{*}{ Major life changes } & $\begin{array}{l}\text { For example, "In the past } 6 \text { months, } \\
\text { have you or someone close to you } \\
\text { been faced with a serious medical } \\
\text { problem or diagnosis?" }\end{array}$ & 4 & & & & & & $x$ \\
\hline & $\begin{array}{l}\text { Mediator variables (also measured } \\
\text { as Outcome Variables) }\end{array}$ & & & & & & & \\
\hline Baseline knowledge & $\begin{array}{l}\text { Knowledge subscales of the } \\
\text { ACP Engagement Survey. }\end{array}$ & 6 & $\begin{array}{l}\text { Cronbach's } a=0.84 \\
(0.76-0.90), I C C=0.70 \\
(0.50-0.82)[15]\end{array}$ & & $x$ & & & \\
\hline Baseline self-efficacy & $\begin{array}{l}\text { Self-efficacy subscales of the } \\
\text { ACP Engagement Survey. }\end{array}$ & 6 & $\begin{array}{l}\text { Cronbach's } a=0.83 \\
(0.75-0.89), I C C=0.60 \\
(0.41-0.76)[15]\end{array}$ & & $x$ & & & \\
\hline Baseline readiness & $\begin{array}{l}\text { Readiness subscales of the } \\
\text { ACP Engagement Survey. }\end{array}$ & 10 & $\begin{array}{l}\text { Cronbach's } a=0.92 \\
(0.88-0.95), I C C=0.60 \\
(0.53-0.81)[15]\end{array}$ & & $x$ & & & \\
\hline Baseline barriers & Checkbox of 13 common barriers & 13 & $\begin{array}{l}\text { Associated with } \\
\text { ACP [25] }\end{array}$ & & $x$ & & & \\
\hline Baseline attitudes & Processes of Change for ACP [16] & 34 & $\begin{array}{l}\text { Responsive to an ACP } \\
\text { intervention [15] }\end{array}$ & & $x$ & & & \\
\hline \multirow[t]{2}{*}{$\begin{array}{l}\text { Desired role in } \\
\text { decision-making }\end{array}$} & Control Preference Scale (CPS) [58] & 2 & $\begin{array}{l}\text { Correlation between } \\
\text { preferred and actual } \\
\text { role in decision- } \\
\text { making [59-61] }\end{array}$ & & $x$ & & & $x$ \\
\hline & Primary Outcome Variables & & & & & & & \\
\hline \multirow[t]{3}{*}{ Full process of ACP } & $\begin{array}{l}\text { ACP Engagement Survey: Process } \\
\text { Measures of knowledge, } \\
\text { contemplation, self-efficacy, } \\
\text { readiness }\end{array}$ & 116 & $\begin{array}{l}\text { Process Measures: Cronbach's } \\
a=0.94(0.91-0.96) \\
\mathrm{ICC}=0.70(0.54-0.82)[15]\end{array}$ & & $x$ & $x$ & $x$ & $x$ \\
\hline & $\begin{array}{l}\text { Action Measures: completion of } \\
\text { advance directives, discussions }\end{array}$ & & $\begin{array}{l}\text { Action Measures: } \\
\mathrm{ICC}=0.87 \\
(0.79-0.92)[15]\end{array}$ & & & & & \\
\hline & Secondary outcome variables & & & & & & & \\
\hline \multirow[t]{2}{*}{ Communication quality } & $\begin{array}{l}\text { Modified CAHPS (that is, did this } \\
\text { provider explain things in a way } \\
\text { that was easy to understand?) }\end{array}$ & 14 & $\begin{array}{l}\text { Comparative Fit } \\
\text { Index }=0.98, \text { Tucker } \\
\text { Lewis Index }=0.98\end{array}$ & & $x$ & $x$ & & \\
\hline & & & $\begin{array}{l}\text { Internal consistency: } \\
0.58 \text { to } 0.92 . \geq 0.70 \\
\text { for four of eight } \\
\text { constructs [62] }\end{array}$ & & & & & \\
\hline $\begin{array}{l}\text { Satisfaction with } \\
\text { communication }\end{array}$ & $\begin{array}{l}\text { For example, "How satisfied are you } \\
\text { that you could share your most } \\
\text { important concerns with X/that X } \\
\text { understood what was most } \\
\text { important to you?) }\end{array}$ & 8 & & & $x$ & $x$ & $x$ & $x$ \\
\hline Satisfaction with care & $\begin{array}{l}\text { Care Consistent with Goals: } \\
\text { Comparison of } 10 \text {-point ratings about } \\
\text { aggressiveness of care desired and } \\
\text { care currently receiving. }\end{array}$ & 4 & & & $x$ & & & $x$ \\
\hline Barriers to ACP & $\begin{array}{l}\text { Checkbox of } 13 \text { common barriers } \\
\text { (for example, thinking about the } \\
\text { topic makes me nervous or sad; I am } \\
\text { too healthy; I am too busy; my family } \\
\text { or doctor is too busy; I prefer to } \\
\text { leave my health in God's } \\
\text { hands; I don't want to } \\
\text { burden my family and } \\
\text { friends; I want to leave } \\
\text { the choice to my friends } \\
\text { and family; I want to leave } \\
\text { the choice to my doctors; } \\
\text { and an open-category } \\
\text { response for "other.") }\end{array}$ & 13 & $\begin{array}{l}\text { Associated with } \\
\text { ACP [25] }\end{array}$ & & $x$ & & & $x$ \\
\hline Attitudes about ACP & $\begin{array}{l}\text { Processes of change for } \\
\text { ACP }[16]\end{array}$ & 34 & $\begin{array}{l}\text { Responsive to ACP } \\
\text { intervention [15] }\end{array}$ & & $x$ & & & \\
\hline
\end{tabular}


Table 2 Constructs and measures for evaluating the efficacy of the PREPARE Study (Continued)

\begin{tabular}{|c|c|c|c|c|c|c|c|c|}
\hline Construct & Measure & \# items & Reliability/validity & Screener & Baseline & 1 week & 3 month & 6 month \\
\hline $\begin{array}{l}\text { Desired role in } \\
\text { decision-making }\end{array}$ & $\begin{array}{l}\text { Control Preference Scale } \\
\text { (CPS) [58] }\end{array}$ & 2 & $\begin{array}{l}\text { Correlation between } \\
\text { preferred and actual } \\
\text { role in decision- } \\
\text { making [59-61] }\end{array}$ & & $x$ & & & $x$ \\
\hline \multirow[t]{2}{*}{$\begin{array}{l}\text { Satisfaction with } \\
\text { decision making }\end{array}$} & \multirow[t]{2}{*}{ Decisional Conflict Scale } & \multirow[t]{2}{*}{20} & $\begin{array}{l}\text { test-retest } \\
\text { coefficient }=0.81\end{array}$ & & & \multirow[t]{2}{*}{$x$} & \multirow[t]{2}{*}{$x$} & \multirow[t]{2}{*}{$x$} \\
\hline & & & $\begin{array}{l}\text { a coefficient: } 0.78-0.92 \\
\text { for total scale. } 0.58- \\
0.92 \text { for subscales [31] }\end{array}$ & & & & & \\
\hline Depression and anxiety & $\begin{array}{l}\text { Patient Health Questionnaire } \\
\text { (PHQ-4) }\end{array}$ & 4 & Cronbach's $a=0.78$ [63] & & $x$ & $x$ & $x$ & $x$ \\
\hline \multirow[t]{5}{*}{$\begin{array}{l}\text { Surrogate reports of patient } \\
\text { engagement in ACP and } \\
\text { other surrogate items }\end{array}$} & $\begin{array}{l}\text { Modified from the ACP } \\
\text { Engagement Survey [22], } \\
\text { (for example, "Did [Veteran] } \\
\text { ask you to be their surrogate } \\
\text { decision maker, talk to you } \\
\text { about leeway, talk to you } \\
\text { about their values, tell other } \\
\text { family or friends about their } \\
\text { wishes, ask clinicians questions } \\
\text { or have you ask clinicians } \\
\text { questions?" }\end{array}$ & 45 & & & & & & \multirow[t]{5}{*}{$x$} \\
\hline & Prior ACP & 6 & & & & & & \\
\hline & Care consistent with goals & 4 & & & & & & \\
\hline & Decisional Conflict & 19 & & & & & & \\
\hline & Implementation & 13 & & & & & & \\
\hline \multirow{5}{*}{$\begin{array}{l}\text { Implementation: } \\
\text { acceptability }\end{array}$} & Acceptability and Usability & & \multirow{5}{*}{$\begin{array}{l}1 \text { factor explained } \\
81-85 \% \text { of variance/ } \\
\text { scale. Kuder- } \\
\text { Richardson >0.75 [12] }\end{array}$} & & $x$ & & & \\
\hline & (a) Ease of use and understanding & 8 & & & & & & \\
\hline & $\begin{array}{l}\text { (b) Usefulness in decisions } \\
\text { \& discussions }\end{array}$ & 6 & & & & & & \\
\hline & $\begin{array}{l}\text { (c) Attitudes about norms } \\
\text { or expectations }\end{array}$ & 6 & & & & & & \\
\hline & $\begin{array}{l}\text { for example, "Did you try to fill out } \\
\text { the advance directive we gave you?" } \\
\text { "Did you give it to a medical provider, } \\
\text { social worker, or case manager?" } \\
\text { If they respond no, "Why do you } \\
\text { think you did not turn it in?" "What } \\
\text { can we do to get other people to } \\
\text { look over these materials?" "What } \\
\text { would motivate them?" "What } \\
\text { suggestions do you have to make } \\
\text { these materials better?" }\end{array}$ & & & & & & & \\
\hline \multirow[t]{6}{*}{$\begin{array}{l}\text { Implementation: } \\
\text { feasibility }\end{array}$} & $\begin{array}{l}\text { Feasibility (Control) (for example, } \\
\text { when and where to review } \\
\text { ACP materials) }\end{array}$ & 7 & & & & & & $x$ \\
\hline & $\begin{array}{l}\text { Feasibility (PREPARE only) (for } \\
\text { example, when and where to } \\
\text { review ACP materials, } \\
\text { and which PREPARE materials } \\
\text { did you use and would recommend) }\end{array}$ & 34 & & & & & & \\
\hline & $\begin{array}{l}\text { "Do you remember what your } \\
\text { action plan was?" }\end{array}$ & & & & & & & \\
\hline & "Did you complete your action plan?" & & & & & & & \\
\hline & $\begin{array}{l}\text { If no to completing an action plan, } \\
\text { "Why do you think you have not } \\
\text { completed your action plan?" }\end{array}$ & & & & & & & \\
\hline & $\begin{array}{l}\text { "After the first study visit, did you } \\
\text { look at the (action plan, summary } \\
\text { of your wishes, the PREPARE website, } \\
\text { pamphlet, Booklet/or DVD) again? }\end{array}$ & & & & & & & \\
\hline
\end{tabular}


Table 2 Constructs and measures for evaluating the efficacy of the PREPARE Study (Continued)

\begin{tabular}{|c|c|c|c|c|c|c|c|c|}
\hline Construct & Measure & \# items & Reliability/validity & Screener & Baseline & 1 week & 3 month & 6 month \\
\hline & $\begin{array}{l}\text { If no, "Why do you think you didn't } \\
\text { you look at it?" }\end{array}$ & & & & & & & \\
\hline & $\begin{array}{l}\text { Satisfaction questions include } \\
\text { "Which of the PREPARE materials } \\
\text { was the most helpful?"; " "Which } \\
\text { would you use again?" "Which } \\
\text { did you share with your decision } \\
\text { maker, friends, or family?" "When } \\
\text { is the best time to see the PREPARE } \\
\text { materials?" "Where do you think most } \\
\text { people would prefer to review the } \\
\text { PREPARE materials (home, clinic, } \\
\text { or public space)? }\end{array}$ & & & & & & & \\
\hline
\end{tabular}

Whereas the mediator variables, measured at baseline, may explain how or why a particular effect or relationship occurs, these variables may also be affected by the intervention and are therefore also measured as outcome variables

materials to others [32]. These outcomes are important to measure to ensure PREPARE will be used in clinical practice and in the community.

\section{Measures related to Veteran activation within primary care encounters}

Veteran activation within the clinical encounter is assessed by audio-recording primary care visits using Dr. Richard Street's communication coding system. This system defines activation as the degree to which patients ask questions, express concerns, offer opinions, state preferences, introduce new topics, or make decisions [33]. These behaviors are considered active because they have been shown to influence clinician's behavior and treatment decisions [19]. We are interested both in activation in general throughout the consultation and in any discussions of ACP [34]. Therefore, we will assess overall activation and ACP-specific activation. The number of activation utterances will be assessed by independent, blinded coders and will be included in a composite measure. Utterances will also be coded as "self-initiated" or "prompted", depending on whether the activation was solicited or encouraged by the physician. An increase of one patient activation utterance is considered clinically relevant. The codes of patient activation will be transformed into quantitative data and stored in a relational database that can be exported for quantitative analysis. To protect against rater drift and decay, continuous monitoring of inter-rater reliability will occur throughout the entire coding period by double-coding $20 \%$ of the conversations. The coders will resolve any coding disagreements by conference; the entire team will resolve persistent disagreements.

\section{Measures related to clinician responsiveness within primary care encounters}

Clinician's responsiveness within the clinical encounter will be assessed by rating "informativeness", participatory decision-making, and partnership building. Overall informativeness will be rated on a 5-point Likert scale by two independent raters from recordings using Dr. Street's previously validated measure based on whether the clinician fully discusses what is causing the patient's problem, the clinician explains everything to the patient, the clinician is very informative about the patient's health, and the clinician's recommendations are clear and easy to understand (score 4 to 20) [34, 35]. ACP-specific informativeness is adapted from this measure and uses the following three items: the clinician thoroughly explained everything about the ACP topic discussed, the clinician was very informative about ACP, and the clinician's explanations about ACP are very clear (score 3 to 15). Clinician's participatory decision-making/partnership building is adapted from Kaplan by Dr. Street [34, 35]. For this measure, independent raters will decide on a 1 to 10 scale $(1=$ not at all and $10=$ a great deal $)$ whether the clinician involved the Veteran in the decisions, gave the Veteran a sense of control over medical care, and asked the Veteran to take some responsibility for ACP or medical care (scores 3 to 30 ).

\section{Measures related to barriers and facilitators of ACP and PREPARE dissemination}

Perceived barriers to engagement in ACP behaviors are assessed with a 10-item survey of the common barriers defined in our prior work and other studies [25].

\section{Input about implementation}

Input about implementation is assessed at 6 months by asking Veterans in the PREPARE arm questions about the acceptability and usability of PREPARE (for example, when and where to review ACP materials, and which PREPARE materials did you use and would recommend). For Veterans in the control arm, we ask about implementation of the ACP materials (for example, when and where to review ACP materials). For Veterans in the PREPARE arm, similar questions are asked of their surrogate decision-makers about the Veterans' use of the PREPARE materials and the surrogates' opinions. 


\section{Outcomes and Sample Size Calculations Primary outcome}

The primary outcome is advance directive documentation in the medical record. This outcome was selected based on prior studies that have shown that advance directive interventions can increase documentation. A meta-analysis demonstrated a pooled effect size of 0.50 (95\% CI; 0.17-0.83) suggesting a positive effect associated with advance directive interventions [36]. One RCT of an ACP workbook in older Veterans also demonstrated an increase in living wills documented from $23 \%$ in controls to $48 \%$ in the intervention group $(P<.001)$; and ACP notes from $24 \%$ to $47 \%(P<.001)$ [37]. Consistent with results from prior studies, our pilot study showed that a literacy appropriate advance directive doubled completion rates from baseline [12]. From SFVAMC administrative data, $11 \%$ of the potential study sample had an advance directive in their medical record. We assume that after being included in the study, the control group may have an advance directive documentation rate of $15 \%$. If we assume doubling of the percent of ACP discussion notes between groups (what we consider clinically significant), a sample size of 350, or 175 in each arm, will afford us $92 \%$ power with a two-tailed alpha of 0.05 to detect an elevation in rate of advance directive documentation from $15 \%$ in controls to $30 \%$ in the PREPARE group and $80 \%$ power to detect a difference of $15 \%$ in controls versus $27 \%$ in the PREPARE group. After accounting for an estimated $15 \%$ attrition rate, including death at 6 months (based on prior work) [12], our recruitment target is 410 Veterans or 205 in each arm.

\section{Secondary outcomes}

The secondary outcomes of this study include a comprehensive range of five specific ACP behaviors: 1) identification of a surrogate, 2) identification of values and goals, 3) choosing the level of leeway or flexibility in decisionmaking for the surrogate, 4) communicating this information with clinicians and surrogate decision-makers, and 5) documenting one's wishes. We hypothesize that the scores from these ACP engagement items could be $50 \%$ higher in the PREPARE group compared to the control group. Based on a pilot, the mean engagement scores for older outpatients were 30.7 points out of $57 \pm$ SD of 10 . Therefore, we expect a mean score as high as 40 points, a 10point average difference between PREPARE and controls. However, even an increase of three points may represent a new action in any of the five domains. Using a two-tailed alpha of $0.05,175$ veterans in each randomization group will give us $>99.9 \%$ power to detect a 10-point difference in engagement score, $96 \%$ power to detect a four-point difference, and $80 \%$ power to detect a three-point difference. A sample size of 350 will also allow us to assess each of the five domains of the preparation engagement survey separately as dichotomous variables, "action taken/no action taken". If we assume a doubling of the percent of Veterans who "took action" within each of the five domains, using a two-tailed alpha of 0.05 , we estimate that 175 veterans in each randomization group will give $92 \%$ power to detect a doubling in the percent of Veterans who "took action" from $15 \%$ (controls) to $30 \%$ (PREPARE group) and $88 \%$ power to detect a difference of $15 \%$ versus 27 $\%$. Taking into account an anticipated $15 \%$ drop out as describe above, our anticipated 410 Veterans or 205 in each arm will provide us ample power to assess these outcomes.

The sample size of 350 Veterans will also allow adequate power to assess interactions based on potential moderating variables (race/ethnicity, literacy, gender) for our outcomes. We also anticipate very low intraclinician correlations due to clustering or contamination; randomization is at the patient level not at the clinician level, and intra-clinician correlation values for patient attitudes and knowledge are typically quite low even in physician-level cluster randomized trials (for example, 0.015) [38]. Furthermore, as we have a potential pool of 115 clinicians, most clinicians will care for no more than one to three eligible Veterans and thus, there will be negligible loss of effective sample size accounting for clustering and contamination.

In exploratory analysis to corroborate Veteran reports of activation, we will attempt to recruit 144 surrogates (72 in each arm) anticipating that $20 \%$ of Veterans will not have identified a surrogate based on pilot data, $15 \%$ of Veterans will be lost to follow-up, and $30 \%$ of surrogates will refuse. For patient activation within clinical encounters, we will attempt to audio-record 200 Veterans (100 in each group) to account for potential $25 \%$ of enrolled Veteran and $25 \%$ clinician refusal rates. For input about implementation, we anticipate recruiting 175 Veterans in the PREPARE arm (accounting for a $15 \%$ drop-out at 6 months) and 72 of PREPARE arm Veteran's surrogates.

\section{Timeline}

Figure 2 shows the timeline of the trial. We started recruitment in April 2013 and will end recruitment of Veterans in September 2015. We are currently undergoing recruitment of surrogate participants and expect to complete recruitment in September 2016.

\section{Data analysis \\ RCT efficacy analysis}

Our primary analyses will compare advance directive completion rates and change in engagement in the five ACP behaviors (see Primary outcome section) using behavior change measure scores on a 5-point Likert scale 


\begin{tabular}{|c|c|c|c|c|c|c|c|c|c|c|c|c|c|c|c|c|c|c|c|c|c|}
\hline \multirow[t]{2}{*}{ Study Phase } & \multirow{2}{*}{\begin{tabular}{|l|} 
Year \\
Month
\end{tabular}} & \multicolumn{4}{|c|}{2012} & \multicolumn{4}{|c|}{2013} & \multicolumn{4}{|c|}{2014} & \multicolumn{4}{|c|}{2015} & \multicolumn{4}{|c|}{2016} \\
\hline & & $\begin{array}{ll}1- \\
3\end{array}$ & $\begin{array}{l}4- \\
6\end{array}$ & $\begin{array}{l}7- \\
9\end{array}$ & $\begin{array}{l}10- \\
12\end{array}$ & $\begin{array}{l}1- \\
3\end{array}$ & $\begin{array}{l}4- \\
6\end{array}$ & \begin{tabular}{|ll}
$7-$ & - \\
9
\end{tabular} & $\begin{array}{l}10- \\
12\end{array}$ & $\begin{array}{ll}1- \\
3\end{array}$ & $\begin{array}{l}4- \\
6\end{array}$ & $\begin{array}{l}7- \\
9\end{array}$ & \begin{tabular}{|l|l}
$10-$ \\
12
\end{tabular} & $\begin{array}{ll}1- \\
3\end{array}$ & $\begin{array}{ll}4- \\
6\end{array}$ & \begin{tabular}{|ll}
$7-$ & - \\
9
\end{tabular} & \begin{tabular}{|l}
$10-$ \\
12
\end{tabular} & $\begin{array}{ll}1- \\
3\end{array}$ & $\begin{array}{l}4- \\
6\end{array}$ & $\begin{array}{l}7- \\
9\end{array}$ & $\begin{array}{l}10- \\
12\end{array}$ \\
\hline \multicolumn{22}{|c|}{ Development of intervention } \\
\hline \multicolumn{22}{|c|}{ Veteran Recruitment } \\
\hline \multicolumn{22}{|c|}{ Surrogate Recruitment } \\
\hline \multicolumn{22}{|c|}{ Intervention } \\
\hline \multicolumn{22}{|l|}{ Assessment } \\
\hline Analysis & & & & & & & & & & & & & & & & & & & & & \\
\hline
\end{tabular}

Fig. 2 PREPARE Study Timeline

(analyzed as average Likert scores and total scores of 57 to 285) and action measure scores using yes and no responses (scores 0 to 25) from baseline to 1 week, and 3, and 6 months between study arms. We first will use means, medians, and ranges to describe continuous variables, and we will use proportions to describe categorical and dichotomous variables. Baseline comparability of the two groups will then be assessed using t-tests for continuous variables and chi-square tests for proportions. To examine the outcomes between the two study arms longitudinally, we will use mixed effects linear, Poisson, or negative binomial regression for continuous outcome measures and mixed effects logistic regression for dichotomous measures. The mixed effects models will include a random effect for subjects and fixed effects for the primary modeling terms of time, study arm, and an interaction term of study arm and time. We will treat the time variable in three different ways: (i) our first model will encode the time variable as a dummy variable for baseline versus the post-intervention time points; (ii) we will next model time in a continuous linear fashion; (iii) we will lastly consider an arbitrary time course by treating time as a categorical factor variable. We will also adjust for the randomization blocking factors of health literacy (limited versus adequate) and race (white versus nonwhite) [39] and for any predictor variables that differ between study arms at baseline. We will also include random physician intercepts to account for nesting of patients within physicians. We will consider including random effects for the primary modeling terms of time, study arm, and their interaction. Modeling decisions (for example, which mean structure to use and which random effects to include) will be based on comparing values of the Akaike Information Criterion. Models will be fit using the xt routines in Stata. Mediation analyses will use Stata's mediation package, which allows estimation of the average causal mediation effect using a potential outcomes framework with either continuous or binary outcomes and allows for sensitivity analyses with respect to violation of the sequential ignorability assumption [40]. Moderating variables will be tested with interaction terms.

\section{Quantitative assessment of patient activation within clinical encounters}

Differences in the number of patient activation utterances, ACP topics discussed, and length of time discussed will be compared between groups using mixed effects models as above with a random intercept for physician. Clinician race/ethnicity, and gender will be included as covariates as these variables are associated with doctor-patient communication [41]. We will also obtain the number of utterances that may signify clinician contamination (knowledge of study arm) to control for these findings.

\section{Discussion}

This is the first study to test the efficacy of a new paradigm of ACP focused on preparing chronically ill older Veterans for communication and medical decision-making as operationalized in the PREPARE website. The development of the PREPARE was based on extensive published formative research in which the community, key stakeholders, and the target population were included in the development of the website. Designed to be easy-to-read and to include culturally competent material, PREPARE is also unique for its user-friendly features such as the use of video modeling of ACP behaviors, tailored and interactive content based on values and decision preferences, and the opportunity to create an action plan for change.

There have been a few logistic challenges to date. Although we attempt to schedule Veteran's baseline appointment and randomization 1 to 3 weeks prior to their most proximate primary care appointment, this, at times, has been difficult to implement for various reasons. For example, some Veterans reschedule their baseline interview resulting in the intervention occurring within a few days before their clinic visit. Other Veterans or the clinic will cancel a primary care appointment after the baseline interview has occurred resulting in a time frame beyond the three-week ideal. We will adjust for these varying time frames from exposure to the intervention in our analyses. In addition, because the audiorecording occurs at the primary care visit and because several primary outcomes of the study would occur at the primary care visit, we decided to make the primary care visit the date from which all follow-up interviews would be calculated. Because follow-up of the 1-week, 
3-month and 6-month interviews within defined time frames was proving challenging, we decided to allow a range of dates that were acceptable. For instance, if a primary care appointment is rescheduled is outside of the ideal 1-3 week window from the baseline interview and randomization, we will audio-record the primary care appointment up to 6 months after the baseline interview, but not after. For the one week follow-up interviews, the allowable Veteran interview range was changed from as early as 5 days from their primary care appointment to as late as 2 weeks prior to their 3-month follow-up; for the 3 -month interview the range is from as early as 2.8 months from the primary care appointment to as late as 2 weeks before the 6-month interview; and for their 6-month interview, the ranges is from as early as 5.8 months from the primary care appointment to as late as 9 months from the appointment.

As described in the methods, surrogate recruitment was initially challenging without the ability to obtain verbal consent. However, this was approved by the IRB office part way through the study. Because surrogate contact takes a great deal of time, we have extended the surrogate recruitment date range to up to 6 months after the Veteran had completed their last 6-month follow-up visit. Even so, there have been several surrogates who were interested but never returned the consent materials, or who returned the consent materials but could not be scheduled before the 6-month cut off. We are hoping that verbal consent will make surrogate interviews easier to obtain.

In addition to testing PREPARE, we hope to be able to disseminate the website broadly. By assessing satisfaction with the PREPARE materials and suggestions for implementation and dissemination during the randomized trial phase, should the results be positive, we hope to move from the efficacy trial phase quickly to implementation and dissemination within the VA and the community.

If PREPARE proves efficacious in helping Veterans engage in ACP, communicate their wishes, better prepare themselves and their loved ones for complex medical decision-making, and document their wishes in the medical record, the PREPARE website could prove to be a scalable and effective intervention to improve the care of older Veterans and ensure Veteran's wishes are honored. Because PREPARE can be used outside of the clinical environment, in future studies it may also save clinicians time and prove to be cost-effective.

\section{Trial status}

This trial is in the active recruitment phase. While we have completed recruitment of 410 Veterans, we anticipate ending surrogate recruitment in September 2016.

\section{Abbreviations}

ACP: advance care planning; SFVAMC: San Francisco Veterans Administration Medical Center; HIPAA: Health Insurance Portability and Accountability Act; $\mathrm{RCT}$ : randomized controlled trial; AD: advance directive; RedCAP: Research Electronic Data Capture.

\section{Competing interests}

There are no competing interests to declare.

\section{Authors' contributions}

$\mathrm{RS}, \mathrm{GL}, \mathrm{RM}, \mathrm{MF}, \mathrm{MK}$, and DB drafted the manuscript; RS and DB designed the study; RS, DB, RM, MF, MK contributed to the conduct of the study; RS, DG, $\mathrm{GL}, \mathrm{RM}, \mathrm{MF}, \mathrm{MK}$ performed critical revisions to the manuscript. All authors read, contributed to, and approved the final manuscript.

\section{Acknowledgements}

The Veterans Affairs Health Services Research \& Development is the primary funder of this study (\#11-110-2). The funder has no role in the study design, the interpretation of data, or the publication of results.

\section{Author details}

'Division of Geriatrics, Department of Medicine, University of California, San Francisco, 3333 California St. Suite 380, San Francisco, CA 94143, USA. ${ }^{2}$ San Francisco Veterans Administration Medical Center, 4150 Clement Street, \#151R, San Francisco, CA 94121, USA. ${ }^{3}$ Division of General Internal Medicine, San Francisco General Hospital, Center for Vulnerable Populations, University of California, San Francisco, 2789 25th Street Suite 350, San Francisco, CA 94110 , USA. ${ }^{4}$ Department of Psychiatry, University of California, San Francisco, CA, USA. ${ }^{5}$ Department of Epidemiology \& Biostatistics, University of California, San Francisco, CA, USA.

Received: 6 October 2015 Accepted: 12 November 2015 Bमt?

\section{References}

1. National Center for Veterans Analysis and Statistics, 2013. http://www.va. gov/vetdata/docs/SpecialReports/Profile_of_Veterans_2013.pdf. Accessed 16 November 2015.

2. Emanuel LL, Barry MJ, Stoeckle JD, Ettelson LM, Emanuel EJ. Advance directives for medical care-a case for greater use. N Engl J Med. 1991;324:889-95.

3. Hofmann JC, Wenger NS, Davis RB, Teno J, Connors Jr AF, Desbiens N, et al. Patient preferences for communication with physicians about end-of-life decisions. SUPPORT Investigators. Study to Understand Prognoses and Preference for Outcomes and Risks of Treatment. Ann Intern Med. 1997;127:1-12.

4. Perkins HS. Controlling death: the false promise of advance directives. Ann Intern Med. 2007;147:51-7.

5. Fried TR, O'Leary JR. Using the experiences of bereaved caregivers to inform patient- and caregiver-centered advance care planning. J Gen Intern Med. 2008;23:1602-7.

6. Anderson WG, Arnold RM, Angus DC, Bryce CL. Posttraumatic stress and complicated grief in family members of patients in the intensive care unit. J Gen Intern Med. 2008;23:1871-6.

7. Vig EK, Starks H, Taylor JS, Hopley EK, Fryer-Edwards K. Surviving surrogate decision-making: what helps and hampers the experience of making medical decisions for others. J Gen Intern Med. 2007;22:1274-9.

8. Wright AA, Zhang B, Ray A, Mack JW, Trice E, Balboni T, et al. Associations between end-of-life discussions, patient mental health, medical care near death, and caregiver bereavement adjustment. JAMA. 2008;300:1665-73.

9. Paasche-Orlow MK, Parker RM, Gazmararian JA, Nielsen-Bohlman LT, Rudd RR. The prevalence of limited health literacy. J Gen Intern Med. 2005;20:175-84.

10. Kutner M, Greenbery E, Baer J. A first look at the literacy of America's adults in the 21st century. Washington DC: National Center for Education Statistics, U.S. Department of Education; 2005.

11. Sudore RL, Fried TR. Redefining the "planning" in advance care planning: Preparing for end-of-life decision-making. Ann Intern Med. 2010;153:256-61.

12. Sudore RL, Landefeld CS, Barnes DE, Lindquist K, Williams BA, Brody R, et al. An advance directive redesigned to meet the literacy level of most adults: a randomized trial. Patient Educ Couns. 2007;69:165-95. 
13. The Institute for Healthcare Advancement: http://www.iha4health.org/ourservices/advance-directive/. Accessed 25 July 2015.

14. Sudore RL, Schickedanz AD, Landefeld CS, Williams BA, Lindquist K, Pantilat SZ, et al. Engagement in multiple steps of the advance care planning process: A descriptive study of diverse older adults. J Am Geriatr Soc. 2008:56:1006-13.

15. Sudore RL, Knight SJ, McMahan RD, Feuz M, Farrell D, Miao Y, et al. A novel website to prepare diverse older adults for decision-making and advance care planning: A pilot study. J Pain Symptom Manage. 2014;47:674-86.

16. Fried $T R$, Redding CA, Robbins ML, Paiva A, O'Leary JR, lannone L. Promoting advance care planning as health behavior change: development of scales to assess Decisional Balance, Medical and Religious Beliefs, and Processes of Change. Patient Educ Couns. 2012;86:25-32.

17. Fried TR, Redding CA, Robbins ML, Paiva A, O'Leary JR, lannone L. Stages of change for the component behaviors of advance care planning. J Am Geriatr Soc. 2010;58:2329-36.

18. Bandura A. Self-efficacy: Toward a unifying theory of behavioral change. Psychol Rev. 1977;84:191-215.

19. Street Jr RL. Interpersonal Communication Skills in Health Care Contexts. In: Greene JO, Burleson BR, editors. Handbook of Communication and Social Interaction Skills. Mawah, New Jersey: Lawrence Erlbaum Associates; 2003. p. 909-33.

20. Spitzburgh BH, Cupach WR. Interpersonal Communication Competence. Beverly Hills, CA: Sage; 1984.

21. Prochaska JO, Velicer WF. The transtheoretical model of health behavior change. Am J Health Promot. 1997;12:38-48.

22. Sudore RL, Stewart AL, Knight SJ, McMahan RD, Feuz M, Miao Y, et al. Development and validation of a questionnaire to detect behavior change in multiple advance care planning behaviors. PLoS One. 2013;8:e72465.

23. Southern DA, Quan H, Ghali WA. Comparison of the Elixhauser and Charlson/Deyo methods of comorbidity measurement in administrative data. Med Care. 2004;42:355-60.

24. Deyo RA, Cherkin DC, Ciol MA. Adapting a clinical comorbidity index for use with ICD-9-CM administrative databases. J Clin Epidemiol. 1992;45:613-9.

25. Schickedanz AD, Schillinger D, Landefeld CS, Knight SJ, Williams BA, Sudore RL. A clinical framework for improving the advance care planning process: start with patients' self-identified barriers. J Am Geriatr Soc. 2009;57:31-9.

26. Whooley MA, Avins AL, Miranda J, Browner WS. Case-finding instruments for depression. Two questions are as good as many. J Gen Intern Med. 1997;12:439-45.

27. Kuslansky G. The Mini-Cog compares well with longer screening tests for detecting dementia in older people. Evid Based Ment Health. 2004;7:38.

28. Pfeiffer E. A short portable mental status questionnaire for the assessment of organic brain deficit in elderly patients. J Am Geriatr Soc. 1975;23:433-41.

29. Sudore RL, Landefeld CS, Williams BA, Barnes DE, Lindquist K, Schillinger D. Use of a modified informed consent process among vulnerable patients: a descriptive study. J Gen Intern Med. 2006;21:867-73.

30. Chew LD, Griffin JM, Partin MR, Noorbaloochi S, Grill JP, Snyder A, et al. Validation of screening questions for limited health literacy in a large VA outpatient population. J Gen Intern Med. 2008;23:561-6.

31. O'Connor AM. Validation of a decisional conflict scale. Med Decis Making. 1995;15:25-30.

32. Volandes AE, Levin TT, Slovin S, Carvajal RD, O'Reilly EM, Keohan ML, et al. Augmenting advance care planning in poor prognosis cancer with a video decision aid: A preintervention-postintervention study. Cancer. 2012;118:4331-8.

33. Street Jr RL, Millay B. Analyzing patient participation in medical encounters. Health Commun. 2001;13:61-73.

34. Street Jr RL, Slee C, Kalauokalani DK, Dean DE, Tancredi DJ, Kravitz RL. Improving physician-patient communication about cancer pain with a tailored education-coaching intervention. Patient Educ Couns. 2010;80:42-7.

35. Kaplan SH, Greenfield S, Gandek B, Rogers WH, Ware Jr JE. Characteristics of physicians with participatory decision-making styles. Ann Intern Med. 1996;124:497-504.

36. Ramsaroop SD, Reid MC, Adelman RD. Completing an advance directive in the primary care setting: what do we need for success? J Am Geriatr Soc. 2007:55:277-83.

37. Pearlman RA, Starks H, Cain KC, Cole WG. Improvements in advance care planning in the Veterans Affairs System: Results of a multifaceted intervention. Arch Intern Med. 2005;165:667-74.

38. Ockene JK, Adams A, Pbert L, Luippold R, Hebert JR, Quirk M, et al. The Physician-Delivered Smoking Intervention Project: Factors that determine how much the physician intervenes with smokers. J Gen Intern Med. 1994:9:379-84.

39. Pocock SJ, Assmann SE, Enos LE, Kasten LE. Subgroup analysis, covariate adjustment and baseline comparisons in clinical trial reporting: Current practice and problems. Stat Med. 2002;21:2917-30.

40. Hicks R, Tingley D. Causal mediation analysis. Stata J. 2011;11:1-15.

41. Gordon HS, Street Jr RL, Sharf BF, Souchek J. Racial differences in doctors' information-giving and patients' participation. Cancer. 2006;107:1313-20.

42. Bergman B, Sjostrand J. A longitudinal study of visual acuity and visual rehabilitation needs in an urban Swedish population followed from the ages of 70 to 97 years of age. Acta Ophthalmol Scand. 2002;80:598-607.

43. Erkinjuntti T, Sulkava R, Wikstrom J, Autio L. Short Portable Mental Status Questionnaire as a screening test for dementia and delirium among the elderly. J Am Geriatr Soc. 1987;35:412-6.

44. Borson S, Scanlan JM, Chen P, Ganguli M. The Mini-Cog as a screen for dementia: Validation in a population-based sample. J Am Geriatr Soc. 2003:51:1451-4.

45. United States Bureau of the Census, http://www.census.gov/topics/ population/language-use.html. Accessed 25 July 2015.

46. Chew LD, Bradley KA, Boyko EJ. Brief questions to identify patients with inadequate health literacy. Fam Med. 2004;36:588-94.

47. Baker DW, Williams MV, Parker RM, Gazmararian JA, Nurss J. Development of a brief test to measure functional health literacy. Patient Educ Couns. 1999;38:33-42

48. Wright AA, Stieglitz H, Kupersztoch YM, Paulk ME, Kim Y, Katz IT, et al. United states acculturation and cancer patients' end-of-life care. PLoS One. 2013;8:e58663.

49. Kahn JR, Fazio EM. Economic status over the life course and racial disparities in health. J Gerontol B Psychol Sci Soc Sci. 2005;60(Spec No 2):76-84.

50. Chen B, Covinsky KE, Stijacic Cenzer I, Adler N, Williams BA. Subjective social status and functional decline in older adults. J Gen Intern Med. 2012;27: 693-9.

51. Lee SJ, Lindquist K, Segal MR, Covinsky KE. Development and validation of a prognostic index for 4-year mortality in older adults. JAMA. 2006;295:801-8.

52. Samper-Ternent R, Kuo YF, Ray LA, Ottenbacher KJ, Markides KS, AI SS. Prevalence of health conditions and predictors of mortality in oldest old Mexican Americans and non-Hispanic whites. J Am Med Dir Assoc. 2012;13:254-9.

53. Shadbolt B, Barresi J, Craft P. Self-rated health as a predictor of survival among patients with advanced cancer. J Clin Oncol. 2002;20:2514-9.

54. Zimmerman M, Ruggero CJ, Chelminski I, Young D, Posternak MA, Friedman M, et al. Developing brief scales for use in clinical practice: The reliability and validity of single-item self-report measures of depression symptom severity, psychosocial impairment due to depression, and quality of life. J Clin Psychiatry. 2006;67:1536-41.

55. Elixhauser A, Steiner C, Harris DR, Coffey RM. Comorbidity measures for use with administrative data. Med Care. 1998;36:8-27.

56. Moser A, Stuck AE, Silliman RA, Ganz PA, Clough-Gorr KM. The eight-item modified Medical Outcomes Study Social Support Survey: Psychometric evaluation showed excellent performance. J Clin Epidemiol. 2012;65:1107-16.

57. Balboni TA, Vanderwerker LC, Block SD, Paulk ME, Lathan CS, Peteet JR, et al. Religiousness and spiritual support among advanced cancer patients and associations with end-of-life treatment preferences and quality of life. J Clin Oncol. 2007;25:555-60.

58. Degner LF, Sloan JA, Venkatesh P. The Control Preferences Scale. Can J Nurs Res. 1997:29:21-43.

59. Degner LF, Sloan JA. Decision-making during serious illness: What role do patients really want to play? J Clin Epidemiol. 1992;45:941-50.

60. Gigerenzer G, Gray JAM. Better Doctors, Better Patients, Better Decisions: Envisioning Health Care 2020. Cambridge: MIT Press; 2011.

61. Singh JA, Sloan JA, Atherton PJ, Smith T, Hack TF, Huschka MM, et al. Preferred roles in treatment decision-making among patients with cancer: A pooled analysis of studies using the Control Preferences Scale. Am J Manag Care. 2010;16:688-96.

62. Weech-Maldonado R, Carle A, Weidmer B, Hurtado M, Ngo-Metzger Q, Hays RD. The Consumer Assessment of Healthcare Providers and Systems (CAHPS) cultural competence (CC) item set. Med Care. 2012;50(9 Suppl 2):S22-31.

63. Lowe B, Wahl I, Rose M, Spitzer C, Glaesmer H, Wingenfeld K, et al. A 4-item measure of depression and anxiety: validation and standardization of the Patient Health Questionnaire-4 (PHQ-4) in the general population. J Affect Disord. 2010;122:86-95. 